\title{
Meta-analysis of efficacy and safety of intravenous ferric carboxymaltose (Ferinject) from clinical trial reports and published trial data
}

\author{
R Andrew Moore ${ }^{1 *}$, Helen Gaskell ${ }^{1,2}$, Peter Rose ${ }^{3}$ and Jonathan Allan ${ }^{4}$
}

\begin{abstract}
Background: Recommendations given for intravenous iron treatment are typically not supported by a high level of evidence. This meta-analysis addressed this by summarising the available date from clinical trials of ferric carboxymaltose using clinical trial reports and published reports.

Methods: Clinical trial reports were supplemented by electronic literature searches comparing ferric carboxymaltose with active comparators or placebo. Various outcomes were sought for efficacy (attainment of normal haemoglobin $(\mathrm{Hb})$, increase of $\mathrm{Hb}$ by a defined amount, for example), together with measures of harm, including serious adverse events and deaths.
\end{abstract}

Results: Fourteen studies were identified with 2,348 randomised patients exposed to ferric carboxymaltose, 832 to oral iron, 762 to placebo, and 384 to intravenous iron sucrose. Additional data were available from cohort studies. Intravenous ferric carboxymaltose was given up to the calculated iron deficit (up to 1,000 mg in one week) for iron deficiency anaemia secondary to chronic kidney disease, blood loss in obstetric and gynaecological conditions, gastrointestinal disease, and other conditions like heart failure. The most common comparator was oral iron, and trials lasted 1 to 24 weeks. Intravenous ferric carboxymaltose improved mean $\mathrm{Hb}$, serum ferritin, and transferrin saturation levels; the mean end-of-trial increase over oral iron was, for $\mathrm{Hb} 4.8$ (95\% confidence interval 3.3 to 6.3) $\mathrm{g} / \mathrm{L}$, for ferritin 163 (153 to 173$) \mu \mathrm{g} / \mathrm{L}$, and for transferrin saturation 5.3\% (3.7 to 6.8\%). Ferric carboxymaltose was significantly better than comparator in achievement of target $\mathrm{Hb}$ increase (number needed to treat (NNT) $6.8 ; 5.3$ to 9.7) and target Hb NNT (5.9; 4.7 to 8.1). Serious adverse events and deaths were similar in incidence in ferric carboxymaltose and comparators; rates of constipation, diarrhoea, and nausea or vomiting were lower than with oral iron.

Conclusions: This review examined the available trials of intravenous ferric carboxymaltose using details from published papers and unpublished clinical trial reports. It increases the evidence available to support recommendations given for intravenous iron treatment, but there are limited trial data comparing different intravenous iron preparations.

\section{Background}

Anaemia is common. A 2008 WHO report concentrating on pre-school children and women estimated that worldwide one in four persons is affected by anaemia, with pregnant women and preschool-age children at the greatest risk [1]. High prevalence of anaemia is

\footnotetext{
* Correspondence: andrew.moore@pru.ox.ac.uk

'Pain Research, Nuffield Department of Anaesthetics, University of Oxford,

Oxford Radcliffe Hospitals, The Churchill, Oxford, OX3 7LJ, UK

Full list of author information is available at the end of the article
}

associated with older age [2], and with acute and chronic conditions, like chronic kidney disease [3].

Blood is expensive. In 2000/2001 the estimated UK NHS cost for an adult transfusion was $£ 635$ for red blood cells (RBC), $£ 378$ for fresh frozen plasma, $£ 347$ for platelets, $£ 834$ for cryoprecipitate, with large increases over the preceding decade [4]. The cost of providing red blood cell transfusions to surgical patients in the USA, including major process steps, staff, consumables, and direct and indirect overhead costs amounted to between US\$522 and US\$1183 [5]. The

\section{Biomed Central}


UK Blood Transfusion Service puts the cost of providing one unit of RBC at about $£ 130$ [6], but the total annual cost of provision and transfusion of blood products was put at $£ 898$ millions in $2000 / 1$, with an annual increase of about $17 \%$ [4].

Despite differences in time and situation, it amounts to an expensive business; it is sensible to avoid these costs and the unnecessary use of blood where possible. There are also potential risks, of incompatibility, infection, and iron overload in patients having recurrent transfusions over long periods.

For iron deficiency anaemia associated with conditions like chronic kidney disease (CKD) the first recourse is to iron supplementation, either oral or parenteral. Anaemia is associated with increased morbidity, and with increased mortality in chronic conditions [7-12], though high $\mathrm{Hb}$ levels may be harmful $[13,14]$. Anaemia is also associated with huge economic burden [15].

For CKD, for example, iron deficiency is a frequent cause of anaemia, resulting from multiple blood sampling, interventional procedures, gastrointestinal bleeding and poor nutritional intake [3]. The severity of iron deficiency anaemia increases with advancing chronic kidney disease, particularly in patients on haemodialysis [16]. The combination of CKD and a low $\mathrm{Hb}$ level occurs in about 100,000 people in the UK [3]. Maintenance of target range Hb levels (11-12 g/dL) in non-dialysis-dependent patients with CKD is associated with positive patient outcomes and improved quality of life and physical function [16]. The complex interrelationships between anaemia and cardiorenal function currently being teased out indicate that we have much to learn [17].

Treatment of iron deficiency anaemia means identifying and treating its cause, and replacing iron may be only part of that $[18,19]$. Oral iron is neither suitable nor effective in all patients; oral iron is poorly absorbed, and is not well tolerated because of adverse gastrointestinal effects [20-22]. Intravenous iron preparations were developed to overcome these problems in patients in whom oral iron is poorly tolerated, or more rapid replacement is required, or absorption is compromised. Intravenous iron preparations have included iron as high or low molecular weight iron dextran, iron gluconate, or iron sucrose, and ferric carboxymaltose; differences include the number of administrations required to replenish iron stores. Some, notably iron dextrans with higher molecular weight, have been associated with hypersensitivity reactions that have limited their use $[23,24]$.

In some conditions, notably CKD, other factors are important, particularly the appropriate balance between stimulation of erythropoiesis and the provision of iron for the manufacture of $\mathrm{Hb}$ [3], and the routine use of erythropoiesis-stimulating agents (ESAs) has led to a need for concomitant iron supplementation. Together, ESAs and iron now form the cornerstone of anaemia management in chronic kidney disease. Intravenous iron supplementation is effective in CKD, with acceptable safety; it permits replacement of iron stores for erythropoiesis, and improves the responsive to ESAs, as well as reducing the requirement for costly ESA therapy and transfusions [22,25-27].

Iron sucrose is typically administered as a slow push injection or a 15- to 30-minute infusion in doses of 100$200 \mathrm{mg}$, requiring multiple outpatient visits and repeated intravenous access for patients to receive the standard therapeutic course of 1,000 mg elemental iron. Iron dextran can be administered as a single dose, but this requires administration over a period of four to six hours. In addition, iron dextran complexes can cause fatal dextran-induced anaphylactic reactions $[3,28]$. Anaphylactic reaction is rare, with estimates for iron dextran products of $0.6 \%$ incidence [29].

Ferric carboxymaltose (Ferinject ${ }^{\circledR}$ ) is a novel non-dextran-containing complex of iron that allows for administration of a large replenishment dose $(\leq 1,000 \mathrm{mg}$ of iron) over a short infusion period (15-30 minutes), typically to the amount required for iron repletion. Ferric carboxymaltose is effective in improving $\mathrm{Hb}$ concentrations in non-dialysis-dependent patients with CKD [30]. It may be of significant benefit for use in the outpatient department or in a community setting as a result of its rapid and high-dose replacement of depleted iron stores in patients with CKD, as well as in various other adult populations with iron deficiency anaemia [30].

It has been noted that many of the recommendations for intravenous iron treatment are not supported by a high level of evidence [31]. This meta-analysis seeks to address the evidence gap by summarising the available data from clinical trials of ferric carboxymaltose using clinical trial reports and published results. Clinical trial reports frequently contain much more detail than is available in published reports, if only because they are not restricted by word count limits; meta-analyses from clinical trial reports of other drugs have been conducted previously [32-34].

\section{Methods}

\section{Identification of studies}

We sought randomised trials and cohort studies of the use of intravenous ferric carboxymaltose for the treatment of iron deficiency anaemia. Studies were included if they treated iron deficiency anaemia, of any cause, for any duration, in patients of any age, and included at least 10 patients. Case reports or informal case series were not eligible.

Vifor Pharma UK Limited provided PDF versions of CTRs of phase $2 / 3$ studies of IV ferric carboxymaltose 
$\left(\right.$ Ferinject $\left.{ }^{\circledR}\right)$, irrespective of clinical condition or design. Published studies were identified by searching PubMED, using as key words Ferinject, ferric carboxymaltose, or iron carboxymaltose in title, abstract, or anywhere in a document. Articles identified were examined online to assess whether they might be a clinical study of efficacy or harm, and hard copy obtained of any regarded as probably being randomised trials or cohort studies. In addition, references of retrieved articles, CTRs, and review articles $[30,35,36]$ were examined for any otherwise unidentified studies.

Electronic searches were conducted originally in June 2010, with additional searches at the time of submission in February 2011. CTRs from Vifor Pharma were of trials with completed reports up to March 2010.

\section{Outcomes sought}

We sought various different outcomes from studies. For efficacy we sought outcomes approximating the following:

- Treatment success, however defined (increase in $\mathrm{Hb}$ by a defined amount, increase in $\mathrm{Hb}$ above a defined level, increase in $\mathrm{Hb}$ plus increases in ferritin and transferrin saturation (TSAT)).

- Attainment of normal $\mathrm{Hb}$, however defined.

- Increase of $\mathrm{Hb}$ by a defined amount.

- Mean increase in $\mathrm{Hb}$ at various times after start of treatment.

- Mean increase in serum ferritin at various times after start of treatment.

- Mean increase in TSAT at various times after start of treatment.

For measures of harm, we sought the following:

- Patients experiencing at least one adverse event.

- Patients experiencing at least one serious adverse event.

- Patients dying.

- Patients experiencing hypertension.

- Patients withdrawing for any reason, because of adverse events, or because of evidence of lack of efficacy (transfusion, introduction of or change in EPO dose, for example).

- Patients experiencing adverse events, as defined by organs or body area.

- Patients with a specific adverse event like constipation or headache.

We also sought any information about change of haematological parameters of $\mathrm{Hb}$, serum ferritin, and TSAT over time.

\section{Analysis}

Data were extracted from studies by one author, and independently verified by another author. Any disagreement was resolved by consensus, and with the aid of another experienced researcher not connected with the review.

Studies were assessed for quality using the Oxford Quality Scale [37]. We defined intention to treat as a patient being randomised and receiving at least one dose of any treatment, and used this as the denominator where possible.

Analyses were planned in the following way:

1. The type of comparator would determine the primary analysis (placebo, oral iron, other IV iron preparation, blood). While combined analysis with different comparators was planned, the main focus would be with the particular comparators for efficacy.

2. Any heterogeneity between clinical conditions would be explored using L'Abbé plots [38], and subgroup analyses if appropriate.

Dichotomous and continuous data were entered into RevMan 5.0 using the appropriate statistic. For dichotomous outcomes, dichotomous data were used to calculate relative benefit or risk (RB, RR) with 95\% confidence intervals (CIs) using a fixed-effect model [39]. The number needed to treat to benefit (NNT) was calculated as the reciprocal of the absolute risk reduction [40]. For unwanted events, the NNT becomes the number needed to treat to harm $(\mathrm{NNH})$, or the number needed to treat to prevent harm (NNTp).

For mean change over time, we planned, for each parameter, to calculate a weighted mean by dividing the sum of the product of mean change in concentration and number of patients of individual studies by the sum of the number of patients in all studies combined.

For all calculations the intention was to pool data for analysis only when available from at least two trials and with data available from at least 400 patients.

\section{Results}

\section{Available studies}

Electronic searches using PubMED produced 33 possible titles; of these eight reports of randomised trials and one report of a cohort study were included (Additional file 1; flow diagram). Vifor provided eleven CTRs. Some published papers duplicated CTRs, some [41-43] did not, and some CTRs contained data that were not published. Identification of possible duplications was achieved by matching condition, numbers enrolled and treated, and patient characteristics between CTRs and published 
studies. One large randomised trial became available after submission, and was included at revision, before resubmission. Of the 11 randomised trials, five scored 5/ 5 , seven scored $3 / 5$ (because they were open studies) and one $2 / 5$; scores of 3 or more out of 5 on this scale are associated with a low potential for bias.

Table 1 shows the sources of information for the available studies and the relationship between CTRs and published studies. Information regarding efficacy or harm was taken from sources that reported them. We finally included 14 unique studies, 11 randomised trials and three cohort studies:

- In iron deficiency anaemia secondary to kidney disease, four studies provided data. Two were randomised, open studies comparing IV ferric carboxymaltose with oral iron $[44,45]$ or IV Venofer (iron sucrose [46]). Two were cohort studies [47-49].

- In iron deficiency anaemia secondary to blood loss during childbirth or associated with heavy uterine bleeding, four randomised, open studies provided data [41,50-55]. All compared IV ferric carboxymaltose with oral iron.

- In iron deficiency anaemia secondary to gastrointestinal causes, one cohort study [56] and one randomised open study $[57,58]$ provided data comparing IV ferric carboxymaltose with oral iron. One randomised trial compared IV ferric carboxymaltose with IV iron sucrose [43].

- Three randomised, double blind studies compared IV ferric carboxymaltose with placebo in different conditions. 1VIT05006 [35,59] was a one-week crossover and CARS-1 [60] was a placebo and active controlled study over 12 weeks in patients with iron deficiency anaemia secondary to several different conditions. In congestive heart failure, IV ferric carboxymaltose was compared with placebo over 24 weeks [42].

- One report of a trial design in patients with iron deficiency anaemia in the setting of non-dialysisdependent chronic kidney disease [61] had no results yet available.

The 14 studies varied in duration between one and 24 weeks and involved 3933 patients, some of whom were exposed to treatments more than once because of crossovers or re-randomisation into extension studies. Therefore 2,348 patients were exposed to IV ferric carboxymaltose in randomised trials and 348 in cohort studies. Oral iron was administered to 832 patients, iron sucrose to 384, and placebo to 762 in randomised trials. Typically, IV ferric carboxymaltose was given up to the calculated iron deficit, with no more than 1,000 mg iron administered in a single week; thereafter smaller doses were given on a regular basis, in, for instance, chronic kidney disease. Details of the study designs, patients participating, and outcomes, are given in Additional file 2 (Trial details).

\section{Efficacy analyses - comparison with oral iron 1 Mean change in values over time}

Five studies comparing IV ferric carboxymaltose with oral iron provided data to allow a calculation of the weighted mean change over time in $\mathrm{Hb}$, serum ferritin, and TSAT $[44,50,52,54,57]$. At least three studies had to provide data for a weighted mean to be calculated at any time period; because studies had different duration (typically up to 12 weeks for randomised studies), calculation of the weighted mean over weeks 6-12 was done with the value available at the longest duration. For ferric carboxymaltose, between 536 and 791 patients contributed data, and for oral iron between 439 and 598 contributed. Estimates of statistical

Table 1 Available studies (NCT = ClinicalTrials.gov registry number)

\begin{tabular}{|c|c|c|c|}
\hline CTR & Condition & NCT & Published study \\
\hline 1VIT04004 [44] & Chronic kidney disease & & Qunibi et al. Nephrol Dial Transplant 2010 doi: 10.1093/ndt/gfa613 [45] \\
\hline 1VIT04005 [47] & Chronic kidney disease & & No publication identified \\
\hline VIT-IV-CL-015 [46] & Haemodialysis & & No publication identified \\
\hline $53214[48]$ & Haemodialysis & & Covic \& Mircescu. Nephrol Dial Transplant 2010 25: 2722-2730 [49] \\
\hline VIT-IV-CL-009 [50] & Post partum anaemia & & Breymann et al. Int J Gynecol Obstet 2008 101: 67-73 [51] \\
\hline 1VIT06011 [52] & Post partum anaemia & & Seid et al. Am J Obstet Gynecol 2008 199:435.e1-7 [53] \\
\hline 1VIT04002/4003 [54] & Uterine bleeding & NCT00395993 & Van Wyck et al. Transfusion 2009 49: 2719-2728 [41] \\
\hline No CTR available & Post partum anaemia & NCT00396292 & Van Wyck et al. Obst \& Gynecol 2007 110:267-278 [55] \\
\hline VIT-IV-CL-03 [56] & Gl causes of anaemia & & No publication identified \\
\hline VIT-IV-CL-008 [57] & Inflammatory bowel disease & & Kulnigg et al. Am J Gastroeneterol 2008 24:1507-1523 [58] \\
\hline 1VIT05006 [59] & Iron deficiency anaemia & & Bailie et al. Hemodialysis International 2010 14: 47-54 [35] \\
\hline CARS $1[60]$ & Iron deficiency anaemia & & No publication identified \\
\hline No CTR available & Congestive heart failure & NCT00520780 & Anker et al. NEJM 2009361 [42] \\
\hline No CTR available & CKD design & NCT00981045 & Szczech et al. Nephrol Dial Transplant 2010 25: 2368-2375 [61] \\
\hline
\end{tabular}


differences were not possible due to differing contributions from studies at different time points, and inconsistent reporting of dispersion.

Following treatment with IV ferric carboxymaltose, the mean $\mathrm{Hb}$ change from baseline increased steadily over weeks 1 to 6 , with a mean increase of about $30 \mathrm{~g} / \mathrm{L}$ by week 6 and sustained at that level to week 12 (Figure 1). With oral iron somewhat smaller increases followed a similar time course.

Following treatment with IV ferric carboxymaltose, the serum ferritin change from baseline declined steadily over weeks 1 to 6 , with a mean increase of about 150 $\mu \mathrm{g} / \mathrm{L}$ by week 6 sustained at that level to week 12 (Figure 2). With oral iron only small changes in serum ferritin occurred.

Following treatment with IV ferric carboxymaltose, the mean TSAT increased steadily from baseline to week 4 and then declined slightly; the mean increase was about $22 \%$ by week 6 and remained at that level at that level to week 12 (Figure 3). With oral iron somewhat smaller increases were seen.

\section{Hb Responders}

Response was defined in various ways: by achieving a target $\mathrm{Hb}$ increase (typically $\geq 20 \mathrm{~g} / \mathrm{L}$ increase), by achieving a target $\mathrm{Hb}$ level (typically $\geq 120 \mathrm{~g} / \mathrm{L}$ ), or by achieving what was typically described as clinical success in the original reports (typically a rise in $\mathrm{Hb}$ of $\geq 20 \mathrm{~g} / \mathrm{L}$ plus ferritin increase of $\geq 150 \mu \mathrm{g} / \mathrm{L}$ or TSAT increase of $\geq 20 \%$ ). Some studies used several of these definitions. Table 2 shows the results of analyses for responders, for all comparators, and for oral iron only. There was good consistency between trial results for all three definitions of responder, with studies demonstrating considerable homogeneity, as the L'Abbé plots in Figures 4, 5, and 6 show.

With IV ferric carboxymaltose $70-80 \%$ of patients achieved target $\mathrm{Hb}$ increases or target $\mathrm{Hb}$ levels,

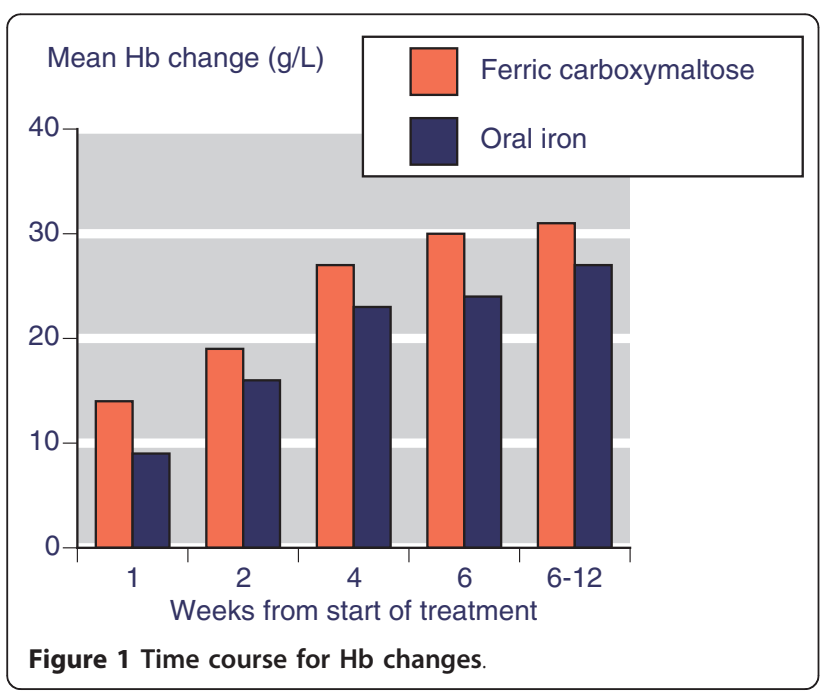

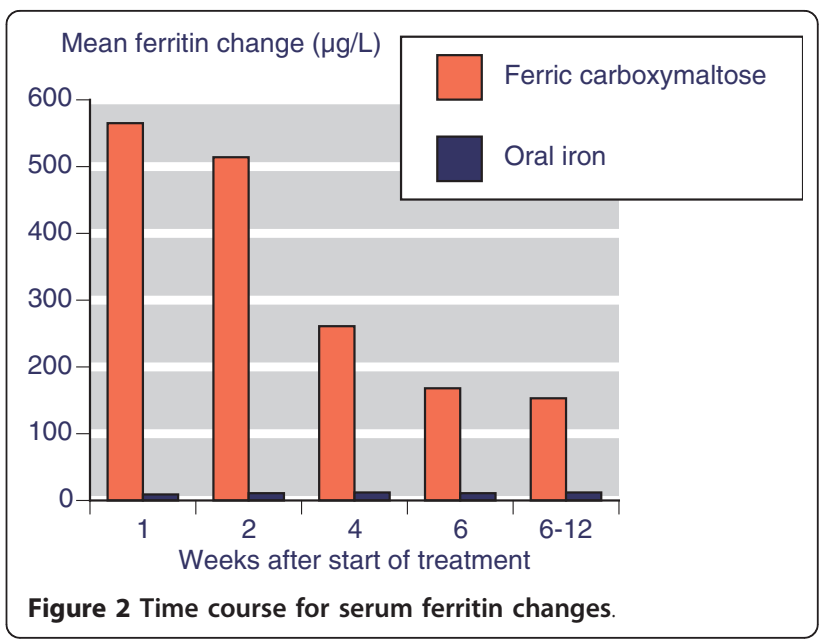

somewhat more than with controls, and producing NNTs of about 6 compared with oral iron. For clinical success similar high levels of response were found for IV ferric carboxymaltose, but the failure of oral iron in particular to increase ferritin levels resulted in low rates of clinical success, with consequent high relative benefit, and low (good) NNTs of about 1.5. The time course of response (Figure 7 ) showed that maximum response rates were typically achieved by 4-6 weeks.

\section{Serum ferritin and TSAT responders}

Responder definitions were also used for serum ferritin and TSAT in three studies $[46,50,57]$. For ferritin the definition was for serum ferritin at four weeks to be between a minimum of 50,100 , or $200 \mu \mathrm{g} / \mathrm{L}$ and a maximum of $800 \mu \mathrm{g} / \mathrm{L}$. This was achieved by about $60 \%$ after IV ferric carboxymaltose, but lower numbers of controls. In comparison with oral iron, the NNT to achieve target ferritin at four weeks was about 3 (Table 3 ). For TSAT, about $65 \%$ achieved target values of being

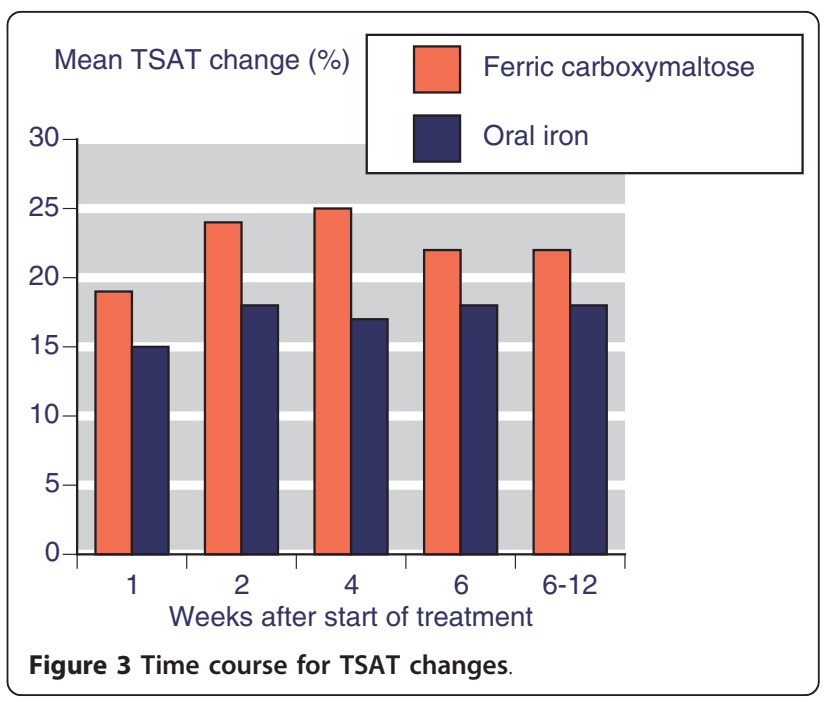


Table $2 \mathrm{Hb}$ responder analysis

\begin{tabular}{|c|c|c|c|c|c|c|c|}
\hline \multirow[b]{2}{*}{ Outcome } & \multirow[b]{2}{*}{ Comparator } & \multicolumn{2}{|c|}{ Number of } & \multicolumn{2}{|c|}{ Percent with } & \multirow[b]{2}{*}{$\begin{array}{c}\mathrm{RB} \\
95 \% \mathrm{Cl} \\
\end{array}$} & \multirow[b]{2}{*}{$\begin{array}{c}\text { NNT } \\
95 \% \mathrm{Cl}\end{array}$} \\
\hline & & Trials & Patients & $\begin{array}{c}\text { Ferric } \\
\text { carboxymaltose }\end{array}$ & Control & & \\
\hline \multirow[t]{2}{*}{ Target $\mathrm{Hb}$ increase } & All & 6 & 1715 & 78 & 63 & $1.2(1.2$ to 1.3$)$ & 6.8 (5.3 to 9.7) \\
\hline & Oral iron & 5 & 1481 & 74 & 59 & $1.3(1.2$ to 1.4$)$ & 6.6 (5.0 to 9.6$)$ \\
\hline Achieve target $\mathrm{Hb}$ level & Oral iron & 5 & 1509 & 79 & 62 & $1.3(1.2$ to 1.4$)$ & $5.9(4.7$ to 8.1$)$ \\
\hline \multirow[t]{2}{*}{ Clinical success } & All & 4 & 1167 & 70 & 2 & 37 (20 to 67) & 1.5 (1.4 to 1.6$)$ \\
\hline & Oral iron & 3 & 984 & 78 & 0 & $250(51$ to 1190$)$ & $1.3(1.2$ to 1.3$)$ \\
\hline
\end{tabular}

in the range of $20-50 \%$ at four weeks with IV ferric carboxymaltose, about the same as with control (Table 3).

\section{Mean changes}

Studies also reported mean changes in $\mathrm{Hb}$, serum ferritin, and TSAT over the duration of the study. Figure 8 shows the difference between IV ferric carboxymaltose and oral iron in five trials reporting data. For $\mathrm{Hb}$, the mean improvement over oral iron was $4.8(95 \% \mathrm{CI} 3.3$ to 6.3) $\mathrm{g} / \mathrm{L}$. For serum ferritin, the mean improvement was $163(95 \%$ CI 153 to 173$) \mu \mathrm{g} / \mathrm{L}$. For TSAT, the mean improvement was $5.3(95 \% \mathrm{CI} 3.7$ to 6.8$) \%$. All were statistically significant improvements over oral iron.

Efficacy analyses - active comparisons and cohort studies One randomised double blind placebo controlled trial provided information on efficacy of IV ferric carboxymaltose in anaemia associated with heart failure.

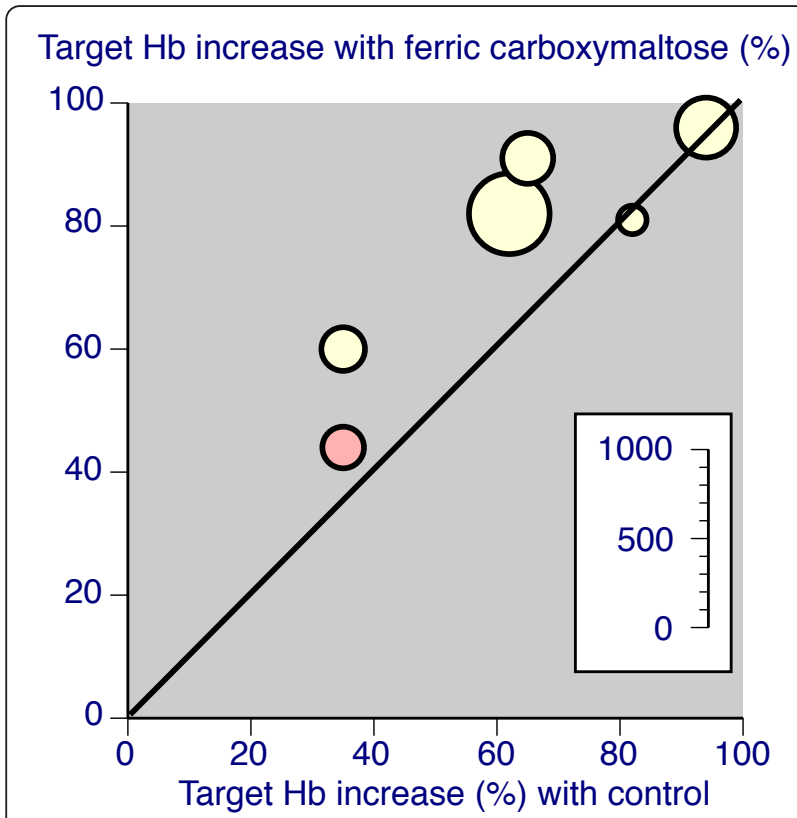

Figure 4 L'Abbé plots for percentage of patients achieving a target $\mathrm{Hb}$ increase (yellow with oral iron comparator, red for intravenous iron sucrose (Venofer)). Each symbol represents one trial, with size of symbol proportional to number of patients randomised using the inset scale.
Another randomised open study compared IV ferric carboxymaltose with IV iron sucrose. Three cohort studies also provided additional information on the use of ferric carboxymaltose.

\section{Active comparisons}

A randomised double blind trial of IV ferric carboxymaltose for treating heart failure randomised 459 patients to IV ferric carboxymaltose or IV placebo, and reported results at 24 weeks, according to initial $\mathrm{Hb}$ level [42]. Half the patients had Hb levels $\leq 120 \mathrm{~g} / \mathrm{L}$ initially, and for these mean final $\mathrm{Hb}$ was higher $(127 \mathrm{~g} / \mathrm{L})$ after IV ferric carboxymaltose than IV placebo (118 g/ L). Final levels of ferritin ( $275 \mathrm{vs} 68 \mu \mathrm{g} / \mathrm{L}$ ) and TSAT ( $29 \%$ vs $17 \%$ ) were also higher after IV ferric carboxymaltose than placebo.

A randomised open trial compared IV ferric carboxymaltose with IV iron sucrose for treating iron deficiency

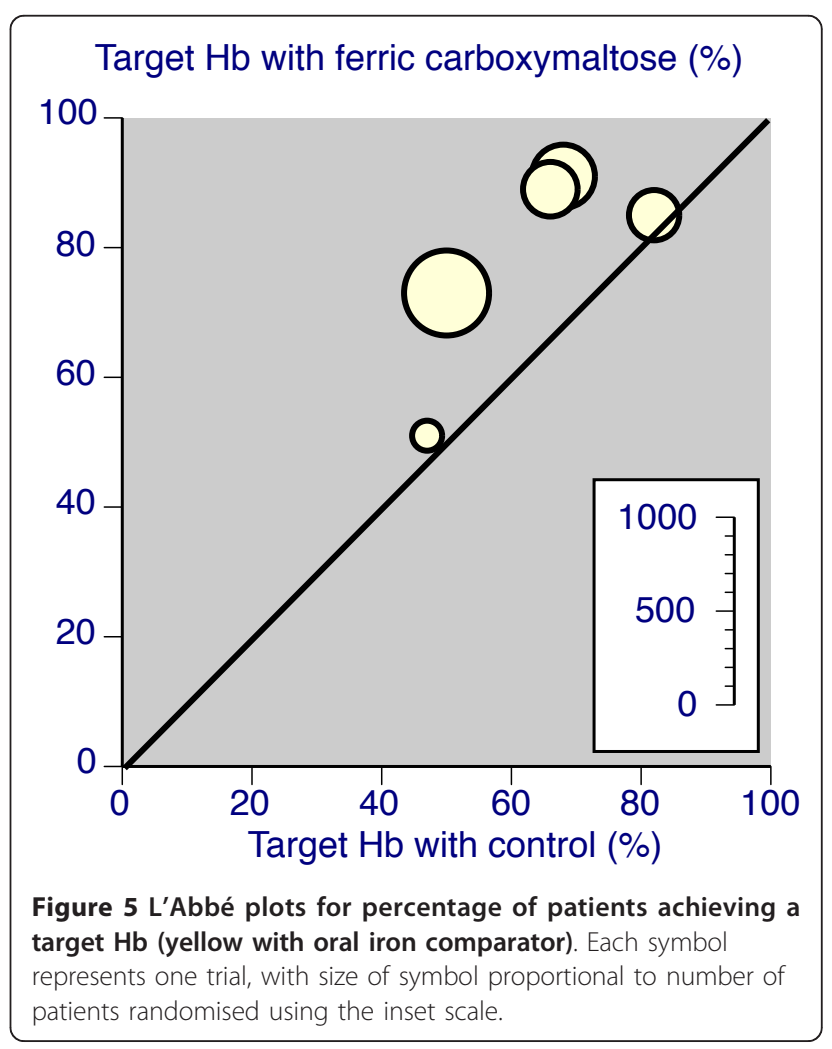




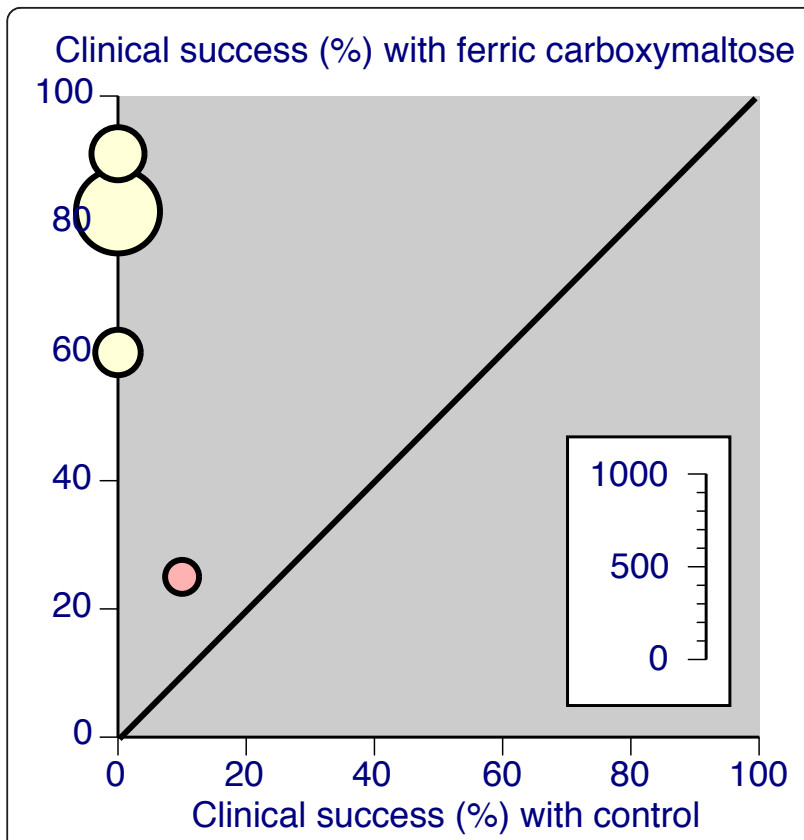

Figure 6 L'Abbé plots for percentage of patients achieving clinical success, however defined (yellow with oral iron comparator, red for intravenous iron sucrose (Venofer)). Each symbol represents one trial, with size of symbol proportional to number of patients randomised using the inset scale.

anaemia secondary to inflammatory bowel disease (ulcerative colitis and Crohn's disease) in 475 patients [43]. Patients had initial $\mathrm{Hb}$ levels below $120 \mathrm{~g} / \mathrm{L}$ in women or $130 \mathrm{~g} / \mathrm{L}$ in men. The primary outcome of increase in $\mathrm{Hb}$ by at least $20 \mathrm{~g} / \mathrm{L}$ was achieved by $66 \%$ with ferric carboxymaltose and 54\% with iron sucrose. Achievement of a normal $\mathrm{Hb}$ occurred in $73 \%$ with ferric carboxymaltose and $62 \%$ for iron sucrose; normal TSAT (20-50\%) was achieved in $53 \%$ and $36 \%$, and normal ferritin $(\geq 100 \mu \mathrm{g} / \mathrm{L})$ by $43 \%$ and $27 \%$ respectively.

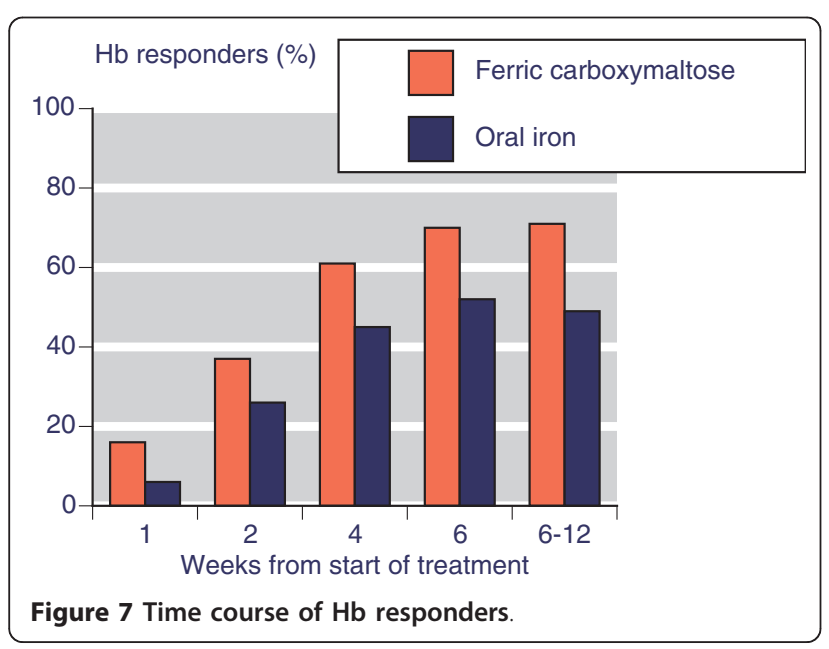

The time course for these changes was similar to that seen in the oral iron comparisons.

This study also compared cost effectiveness of the two regimens. Although ferric carboxymaltose has a higher cost per treatment than iron sucrose (US\$ 311 vs 154), the greater number of infusions with iron sucrose resulted in a higher overall treatment cost (US\$ 653 for ferric carboxymaltose and US\$ 891 for iron sucrose). Treatment with iron sucrose thus costs US\$ 238 more than ferric carboxymaltose, but with a $12 \%$ lower chance of hitting the target increase in $\mathrm{Hb}$.

\section{Cohort studies}

In a non-randomised extension study in patients with kidney disease [47] where treatment duration (up to 43 weeks) depended on the degree of anaemia, IV ferric carboxymaltose resulted in a mean $\mathrm{Hb}$ increase of $19 \mathrm{~g} /$ $\mathrm{L}$ and clinical success $(\mathrm{Hb} \geq 100 \mathrm{~g} / \mathrm{L}$, ferritin 100-800 $\mu \mathrm{g} / \mathrm{L}$, TSAT $30-50 \%)$ of $72 / 140$ (51\%). Most patients had serum ferritin in the range 100-800 $\mu \mathrm{g} / \mathrm{L}(99 \%)$, and TSAT $30-50 \%$ (76\%).

An open cohort study in patients receiving haemodialysis lasting 10 weeks, with $200 \mathrm{mg}$ IV ferric carboxymaltose two or three times a week during haemodialysis sessions [48] produced a mean increase in $\mathrm{Hb}$ of $10 \mathrm{~g} / \mathrm{L}$, with $73 \%$ and $82 \%$ of patients with more than $10 \mathrm{~g} / \mathrm{L}$ at 2 and 4 weeks. The mean ferritin increase was $403 \mu \mathrm{g} / \mathrm{L}$, and TSAT increase $16 \%$.

In anaemia secondary to a gastrointestinal disorder, 46 patients were given either $500 \mathrm{mg}$ IV ferric carboxymaltose weekly for four weeks or $1000 \mathrm{mg}$ weekly for two weeks [56]. Most patients had increases in $\mathrm{Hb}$ of $\geq 20 \mathrm{~g} /$ $\mathrm{L}$, with $34 / 46$ (74\%) having normal $\mathrm{Hb}(\geq 140 \mathrm{~g} / \mathrm{L}$ for men and $\geq 120 \mathrm{~g} / \mathrm{L}$ for women). The mean $\mathrm{Hb}$ increase was above $20 \mathrm{~g} / \mathrm{L}$.

\section{Withdrawals and adverse events - comparison with oral iron \\ 1 Withdrawal}

All cause withdrawals, in all randomised studies combined, were slightly less frequent with IV ferric carboxymaltose than with controls (oral iron, IV iron, and IV placebo; Table 4), though only by about $1 \%$ (NNT to prevent one withdrawal 93). There was no significant difference in the comparison with oral iron, nor was there any significant difference between IV ferric carboxymaltose and any control for adverse event or lack of efficacy withdrawal.

\section{Adverse events}

No significant difference was found between IV ferric carboxymaltose for patients experiencing at least one adverse event, death, and any serious adverse event. For hypotension, IV ferric carboxymaltose produced significantly more events than oral iron, with a NNH of 79 (Table 4). Hypotension associated with IV ferric carboxymaltose was not a factor in any deaths. 
Table 3 Serum ferritin and TSAT responder analysis

\begin{tabular}{|c|c|c|c|c|c|c|c|}
\hline \multirow[b]{2}{*}{ Outcome } & \multirow[b]{2}{*}{ Comparator } & \multicolumn{2}{|c|}{ Number of } & \multicolumn{2}{|c|}{ Percent with } & \multirow[b]{2}{*}{$\begin{array}{c}\text { RB } \\
95 \% \mathrm{Cl}\end{array}$} & \multirow[b]{2}{*}{$\begin{array}{c}\text { NNT } \\
95 \% \mathrm{Cl}\end{array}$} \\
\hline & & Trials & Patients & $\begin{array}{c}\text { Ferric } \\
\text { carboxymaltose }\end{array}$ & Control & & \\
\hline \multirow[t]{2}{*}{ Target ferritin increase } & All & 3 & 611 & 61 & 43 & 1.6 (1.3 to 1.9$)$ & 5.6 (3.9 to 10$)$ \\
\hline & Oral iron & 2 & 428 & 59 & 22 & 2.7 (2.0 to 3.6 ) & 2.7 (2.2 to 3.6 ) \\
\hline \multirow[t]{2}{*}{ Target TSAT increase } & All & 3 & 611 & 65 & 62 & 1.1 (0.9 to 1.2 ) & not calculated \\
\hline & Oral iron & 2 & 428 & 64 & 59 & 1.1 (0.9 to 1.3$)$ & not calculated \\
\hline
\end{tabular}

\section{Adverse events by body systems}

Adverse events were reported according to body systems, and Table 5 shows analyses for IV ferric carboxymaltose compared with oral iron and with IV placebo. In the comparison with oral iron, IV ferric carboxymaltose produced fewer gastrointestinal events (13\% compared with $32 \%$, NNTp 5), but more general and administrative site events (NNH 15) and abnormalities in metabolism, nutrition, and investigations ( $\mathrm{NNH} \mathrm{17).}$
Compared with IV placebo, IV ferric carboxymaltose produced more gastrointestinal and general and administrative site events (NNH 34 and 25, respectively).

\section{Specific adverse events}

Table 5 also shows specific adverse events mentioned in at least three comparisons between IV ferric carboxymaltose and oral iron. IV ferric carboxymaltose produced less constipation ( $3 \%$ vs $13 \%$, NNTp 10), nausea and vomiting ( $3 \%$ vs $10 \%$, NNTp 14 ), and diarrhoea ( $2 \%$ vs $5 \%$, NNTp 33 ).

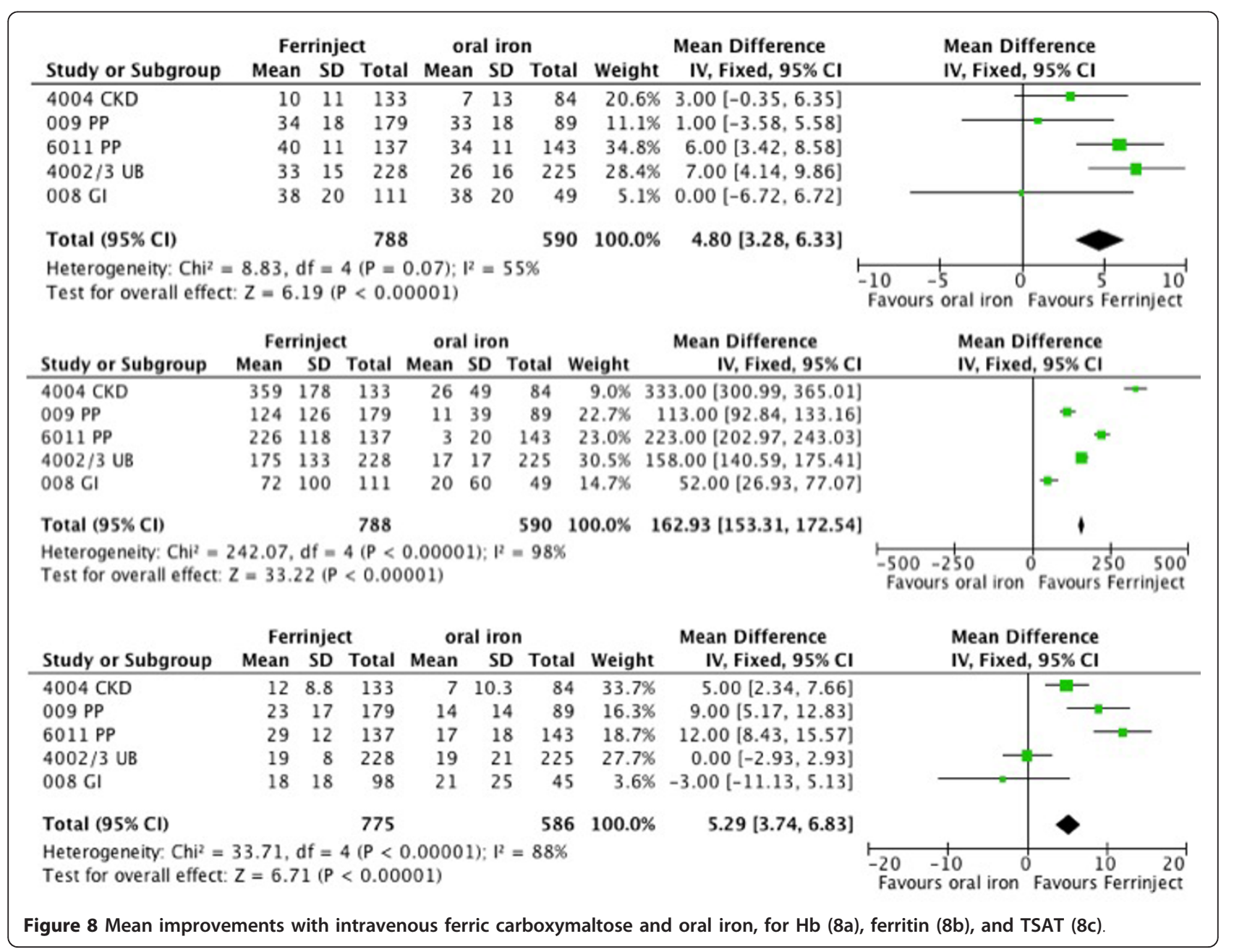


Table 4 Withdrawals and adverse events

\begin{tabular}{|c|c|c|c|c|c|c|c|}
\hline \multirow[b]{2}{*}{ Outcome } & \multirow[b]{2}{*}{ Comparator } & \multicolumn{2}{|c|}{ Number of } & \multicolumn{2}{|c|}{ Percent with } & \multirow[b]{2}{*}{$\begin{array}{c}\text { RB or RR } \\
95 \% \mathrm{Cl} \\
\end{array}$} & \multirow[b]{2}{*}{$\begin{array}{l}\text { NNTp } \\
95 \% \mathrm{Cl} \\
\end{array}$} \\
\hline & & Trials & Patients & $\begin{array}{c}\text { Ferric } \\
\text { carboxymaltose }\end{array}$ & Control & & \\
\hline \multicolumn{8}{|l|}{ Withdrawals } \\
\hline \multirow[t]{2}{*}{ All cause } & All & 10 & 3835 & 6.4 & 7.5 & 0.8 (0.6 to 0.9 ) & 93 (37 to 180$)$ \\
\hline & Oral iron & 6 & 1898 & 8.1 & 9.3 & 0.8 (0.6 to 1.03 ) & not calculated \\
\hline \multirow[t]{2}{*}{ Adverse event } & All & 8 & 3319 & 1.0 & 1.6 & 0.6 (0.3 to 1.02 ) & not calculated \\
\hline & Oral iron & 6 & 1898 & 1.5 & 1.9 & 0.7 (0.3 to 1.4$)$ & not calculated \\
\hline \multirow[t]{2}{*}{ Lack of efficacy } & All & 7 & 2967 & 0.6 & 0.8 & 0.8 (0.4 to 1.7$)$ & not calculated \\
\hline & Oral iron & 5 & 1546 & 1.1 & 1.2 & 0.8 (0.4 to 1.9 ) & not calculated \\
\hline Adverse events & & & & & & & $\begin{array}{c}\mathrm{NNH} \\
95 \% \mathrm{Cl}\end{array}$ \\
\hline \multirow[t]{2}{*}{ At least $1 \mathrm{AE}$} & All & 8 & 2951 & 41 & 38 & 1.1 (1.0 to 1.2 ) & not calculated \\
\hline & Oral iron & 5 & 1539 & 48 & 53 & $1.0(0.9$ to 1.1$)$ & not calculated \\
\hline \multirow[t]{2}{*}{ Death } & All & 10 & 3762 & 0.53 & 0.3 & 1.3 (0.5 to 3.4$)$ & not calculated \\
\hline & Oral iron & 6 & 1891 & 0.38 & 0.0 & 1.7 (0.4 to 6.6) & not calculated \\
\hline \multirow[t]{2}{*}{ Serious AE } & All & 8 & 3303 & 2.5 & 2.3 & 1.0 (0.6 to 1.5$)$ & not calculated \\
\hline & Oral iron & 6 & 1891 & 3.1 & 2.3 & 1.3 (0.7 to 2.2) & not calculated \\
\hline \multirow[t]{2}{*}{ Hypotension } & All & 6 & 2694 & 1.5 & 1.0 & 1.5 (0.8 to 2.7) & not calculated \\
\hline & Oral iron & 4 & 1339 & 1.3 & 0.0 & 4.7 (1.1 to 21$)$ & 79 (44 to 390$)$ \\
\hline
\end{tabular}

Adverse events - active comparisons and cohort studies In the randomised comparison of IV ferric carboxymaltose with IV placebo in patients with heart failure [42], all cause withdrawal occurred in $9 \%$ of patients on ferric carboxymaltose and $13 \%$ with placebo. Deaths occurred less frequently with ferric carboxymaltose $(5 / 304,1.6 \%)$ than with placebo $(4 / 155,2.6 \%)$. The randomised comparison of IV ferric carboxymaltose with IV ferric sucrose in inflammatory bowel disease [43] led to few all cause withdrawals ( $9 \%$ vs $11 \%$ ), and few patients reported any adverse event (14\% vs $11 \%)$. One serious adverse event was reported with ferric carboxymaltose,

Table 5 Adverse events by body system and specific adverse events

\begin{tabular}{|c|c|c|c|c|c|c|}
\hline \multirow[b]{2}{*}{ Outcome } & \multicolumn{2}{|c|}{ Number of } & \multicolumn{2}{|c|}{ Percent with } & \multirow[b]{2}{*}{$\begin{array}{l}\text { RB or RR } \\
95 \% \mathrm{Cl}\end{array}$} & \multirow[b]{2}{*}{$\begin{array}{l}\text { NNTp/H } \\
95 \% \mathrm{Cl}\end{array}$} \\
\hline & Trials & Patients & $\begin{array}{c}\text { Ferric } \\
\text { carboxymaltose }\end{array}$ & Control & & \\
\hline \multicolumn{7}{|c|}{ Comparison with oral iron } \\
\hline \multicolumn{7}{|l|}{ Body system and preferred term } \\
\hline Gl disorder & 5 & 1539 & 13 & 32 & 0.44 (0.36 to 0.54$)$ & $5.4(4.4$ to 7.1$)$ \\
\hline General, administrative site & 5 & 1539 & 11 & 4 & 2.8 (1.9 to 4.2$)$ & 15 (11 to 24$)$ \\
\hline Infection, infestation & 5 & 1539 & 14 & 12 & $1.2(0.9$ to 1.6$)$ & not calculated \\
\hline Metabolism, nutrition, investigation & 4 & 1195 & 11 & 5 & $2.2(1.4$ to 3.4$)$ & 17 (11 to 33$)$ \\
\hline Nervous system & 5 & 1539 & 10 & 9 & $1.3(0.9$ to 1.7$)$ & not calculated \\
\hline \multicolumn{7}{|l|}{ Specific adverse events } \\
\hline Constipation & 4 & 1339 & 3 & 13 & $0.3(0.2$ to 0.4$)$ & 9.8 (7.6 to 14$)$ \\
\hline Diarrhoea & 3 & 906 & 2 & 5 & 0.5 (0.2 to 0.9$)$ & 33 (18 to 230$)$ \\
\hline Nausea/vomiting & 3 & 906 & 3 & 10 & $0.4(0.2$ to 0.6$)$ & 14 (9.5 to 27$)$ \\
\hline Headache & 5 & 1539 & 7 & 7 & $1.2(0.8$ to 1.7$)$ & not calculated \\
\hline \multicolumn{7}{|c|}{ Comparison with IV saline } \\
\hline \multicolumn{7}{|l|}{ Body system and preferred term } \\
\hline Gl disorder & 2 & 1577 & 8 & 5 & $1.6(1.1$ to 2.4$)$ & $34(19$ to 210$)$ \\
\hline General, administrative site & 2 & 1577 & 6 & 2 & 2.5 (1.5 to 4.3$)$ & 25 (17 to 49 ) \\
\hline Infection, infestation & 2 & 1577 & 9 & 6 & $1.1(0.8$ to 1.6$)$ & not calculated \\
\hline Nervous system & 2 & 1577 & 8 & 6 & $1.2(0.9$ to 1.8$)$ & not calculated \\
\hline Respiratory system & 2 & 1577 & 2 & 2 & $0.8(0.4$ to 1.5$)$ & not calculated \\
\hline
\end{tabular}

Note NNTp in normal text, NNH when bold 
and no deaths in this young population (median age 39 years).

In the three cohort studies $[47,48,56] 345$ patients were treated with IV ferric carboxymaltose. Of these 75 (21\%) withdrew for any reason, and 14 (4\%) because of adverse events. At least one adverse event was experienced by 197 (56\%), serious adverse events by $35(10 \%)$, and hypotension by $10(3 \%)$.

\section{Death - all studies}

There were 20 deaths. These occurred in 15 patients treated with ferric carboxymaltose because of unstated cardiovascular causes (4), myocardial infarction after withdrawal, cardiac arrest, peripartum cardiomyopathy, acute heart failure, prostate cancer, trauma, perforation following diverticulitis, gastrointestinal bleeding following laparoscopy, pulmonary tuberculosis, infection with Aeromonas pulmoniae, and one unknown cause. With iron sucrose there was one death from cardiac failure, and for placebo there were four deaths with unstated cardiovascular causes. Crude mortality rates were $0.6 \%$ $(15 / 2696)$ with IV ferric carboxymaltose, $0.3 \%(1 / 382)$ with IV iron sucrose, $0.5 \%(4 / 762)$ with placebo, and $0 \%$ $(0 / 832)$ with oral iron.

\section{Discussion}

Our knowledge of iron metabolism is still in a state of rapid development [62-64], but however involved it may turn out, we have to interpret the evidence from completed studies on the basis of the tests used at the time. In the case of the ferric carboxymaltose studies, this meant mainly $\mathrm{Hb}$, serum ferritin, and TSAT. Complications arise when assessing the evidence on anaemia in different conditions and with different causes (chronic kidney disease, uterine or postpartum bleeding, gastrointestinal disease, heart failure), using different comparators (oral iron, IV iron, placebo), and from patients receiving erythropoietin. Moreover, haematological outcomes are reported in different ways, typically average change in value, or response or nonresponse, but with differing definitions of response. Trials also had different regimens for giving IV iron, mainly because of different clinical requirements.

Unfortunately some randomised studies were not blind, and others were non-comparative, which does weaken the strength of the evidence available. Set against this were the relatively large numbers of patients reported on, often concerning appropriate duration, and the consistency of response not only between different trials for similar outcomes, but also between randomised and non-comparative studies. A further strength was the availability of CTRs as well as published articles for a number of trials. CTRs are much more detailed than published reports because they are not constrained by word limits, or limits on tables and figures. Most CTRs, for example, comprised over 100 pages, and at least one over 1,000 pages of details. CTRs have been used for a number of meta-analyses where more insightful examination of clinical trials has been needed. They have been used, for example, in reporting adverse events [33], and determining different outcomes in erectile dysfunction [32] and pain [65].

Comparing IV ferric carboxymaltose with oral iron showed a similar time course for $\mathrm{Hb}$ and TSAT, though at each time point results for oral iron were numerically worse. Oral iron had no effect on ferritin. Where response was defined as achievement of target $\mathrm{Hb}$, preset $\mathrm{Hb}$ rise, or preset $\mathrm{Hb}$ rise together with preset changes in ferritin and/or TSAT, there was a statistically significantly better result for ferric carboxymaltose, with NNTs in the range of 6-7, but as low as 1.5 when clinical success was defined with ferritin changes. The much lower, better, NNT reflected the lack of any effect of oral iron on serum ferritin. However response was defined, the response rate with ferric carboxymaltose was in the range of $70-80 \%$ (Table 2).

Ferric carboxymaltose produced significantly greater improvements in mean $\mathrm{Hb}$, ferritin, and TSAT in the five trials that compared them, with an average improvement of about $5 \mathrm{~g} / \mathrm{L}, 163 \mu \mathrm{g} / \mathrm{L}$, and $5 \%$ respectively (Figure 6). These figures were obtained at the end of the trials when the increase in ferritin seen soon after therapy started had declined (Figure 2).

In general, and with large numbers of patients, there was little difference in terms of withdrawals and adverse events, including serious adverse events or hypotension, between ferric carboxymaltose and all comparators or oral iron alone.

There were more deaths in the trial arms using ferric carboxymaltose than with control; they were no more frequent than with placebo or iron sucrose, at between $0.3 \%$ and $0.6 \%$, though none occurred with oral iron. In the largest and longest study compared with placebo, death rates were similar in the two groups, and 5 of the 11 deaths with ferric carboxymaltose occurred in that trial [42]. Recent reanalyses of trials of ESAs points to rapid $\mathrm{Hb}$ increases as being associated with higher mortality risk [66]. If that finding were replicated with IV iron, with or without use of ESA, it might point to a mechanism where too rapid restoration of iron stores was also associated with an increased mortality risk. The emerging view is that serious adverse events have declined with newer IV iron preparations, such that benefits outweigh any risks [67].

In terms of specific adverse events, ferric carboxymaltose was associated with lower rates of constipation, diarrhoea and nausea or vomiting than oral iron, but injection site reactions were higher compared to other parenteral iron preparations. 
It is worth mentioning several points that this analysis was not able to assess. For example, no studies compared ferric carboxymaltose with blood transfusion, and direct comparisons between different IV iron products were limited in number, but clearly of interest. This limited the comparison mainly to that between IV ferric carboxymaltose and oral iron. The rate of decline in $\mathrm{Hb}$ after stopping treatment with ferric carboxymaltose or oral iron would have been of interest, particularly in some patient groups. This review goes some way to improving the level of evidence available to support recommendations given for IV iron treatment [38], but is not yet a complete response because of the lack of clinical trials. The review was also limited in being able to obtain useful health economic data except from one recent trial [43] that demonstrated a lower cost for IV ferric carboxymaltose over IV iron sucrose, but with a higher success rate. Recent analyses also show that not treating anaemia in CKD with IV iron or ESAs led to greater mortality and cost [68].

\section{Conclusions}

There is substantial evidence that IV ferric carboxymaltose is effective in treating iron deficiency anaemia in many chronic conditions. The review increases the evidence available to support recommendations given for IV iron treatment, but there are limited trial data comparing different IV iron preparations.

\section{Authors information}

RAM - MA DPhil CChem FRSC FRCA DSc - has been involved with systematic reviews and meta-analyses, and method development in pain and other areas

HG - BM BCh DPhil MRCGP - works in secondary care and evidence-based medicine

PR - FRCP FRCPath - has been involved in prospective clinical trials, systematic reviews, meta-analysis and production of clinical guidelines in Haemostasis and Thrombosis.

JA - MRPharms DipClinPharm - specialising in haematology.

\section{Additional material}

Additional file 1: Flowchart of searches.

Additional file 2: Details of individual studies.

\section{List of abbreviations}

Cl: confidence interval; CKD: chronic kidney disease; CTR: clinical trial report; EPO: erythropoietin; ESA: erythropoiesis-stimulating agents; $\mathrm{Hb}$ : haemoglobin; IV: intravenous; NCT: National Clinical Trials Identifier; NNH: number needed to harm; NNT: number needed to treat; NNTp: number needed to treat to prevent; RB: relative benefit; RR: relative risk; TSAT: transferrin saturation; WHO: World Health Organisation.

\section{Acknowledgements and funding}

Financial support for this project was provided by Vifor Pharma UK. Other funding was from Pain Research funds of the Oxford Pain Relief Trust. No funding source had any role in deciding whether to publish, what to publish, when to publish, or where to publish it.

\section{Author details}

${ }^{1}$ Pain Research, Nuffield Department of Anaesthetics, University of Oxford, Oxford Radcliffe Hospitals, The Churchill, Oxford, OX3 7LJ, UK. ${ }^{2}$ Department of Clinical Gerontology, John Radcliffe Hospital, Oxford, OX3 9DU, UK. ${ }^{3}$ Haematology Department, Warwick Hospital, Lakin Road, Warwick, CV35 5BW, UK. ${ }^{4}$ Pharmacy Department, Beatson West of Scotland Cancer Centre, Glasgow, G12 OYN, UK.

\section{Authors' contributions}

RAM and HG were involved with the original concept, planning the study, writing it, analysis, and preparing a manuscript; PR and JA read the paper as it developed and guided its development. All authors read and approved the final manuscript.

\section{Competing interests}

The authors declare that they have no competing interests.

Received: 9 March 2011 Accepted: 24 September 2011

Published: 24 September 2011

\section{References}

1. de Benoist B, McLean E, Egli I, Cogswell M: Worldwide prevalence of anaemia 1993-2005. WHO Global Database on Anaemia, World Health Organisation; 2008

2. Gaskell H, Derry S, Andrew Moore R, McQuay HJ: Prevalence of anaemia in older persons: systematic review. BMC Geriatr 2008, 8:1.

3. National Institute for Health and Clinical Excellence: Clinical guideline 39: Anaemia management in people with chronic kidney disease (CKD). 2006 [http://guidance.nice.org.uk/CG39], (last accessed February 3 2011).

4. Varney SJ, Guest JF: The annual cost of blood transfusions in the UK. Transfus Med 2003, 13:205-218.

5. Shander A, Hofmann A, Ozawa S, Theusinger OM, Gombotz H, Spahn DR: Activity-based costs of blood transfusions in surgical patients at four hospitals. Transfusion 2010, 50:753-765.

6. NHS Blood and Transplant: Annual review 2010.[http://www.nhsbt.nhs.uk/ annualreview], (last accessed February 3 2011).

7. McClellan WM, Flanders WD, Langston RD, Jurkovitz C, Presley R: Anemia and renal insufficiency are independent risk factors for death among patients with congestive heart failure admitted to community hospitals: a population-based study. J Am Soc Nephrol 2002, 13:928-1936.

8. Mozaffarian D, Nye R, Levy WC: Anemia predicts mortality in severe heart failure: the prospective randomized amlodipine survival evaluation (PRAISE). J Am Coll Cardiol 2003, 41:1933-1939.

9. Langston RD, Presley R, Flanders WD, McClellan WM: Renal insufficiency and anemia are independent risk factors for death among people with acute myocardial infarction. Kidney Int 2003, 64:1398-1405.

10. Patel KV, Longo DL, Ershler WB, Yu B, Semba RD, Ferrucci L, Guralnik JM Haemoglobin concentration and the risk of death in older adults: differences by race/ethnicity in the NHANES III follow-up. Br I Haematol 2009, 145:514-523.

11. Teng TH, Finn J, Hung J: Mild anaemia is associated with increased allcause mortality in heart failure. Heart Lung Circ 2010, 19:31-37.

12. Zoppini G, Targher G, Chonchol M, Negri C, Stoico V, Pichiri I, Lippi G, Muggeo M, Bonora E: Anaemia, independent of chronic kidney disease, predicts all-cause and cardiovascular mortality in type 2 diabetic patients. Atherosclerosis 2010, 210:575-580.

13. Phrommintikul A, Haas SJ, Elsik M, Krum H: Mortality and target haemoglobin concentrations in anaemic patients with chronic kidney disease treated with erythropoietin: a meta-analysis. Lancet 2007, 369:381-388

14. Shander A, Cappellini MD, Goodnough LT: Iron overload and toxicity: the hidden risk of multiple blood transfusions. Vox Sang 2009, 97:185-197.

15. Ershler WB, Chen K, Reyes EB, Dubois R: Economic burden of patients with anemia in selected diseases. Value Health 2005, 8:629-638. 
16. Pugh-Clarke K, Cooper L, Turner J, Fermin J: An evidence-based approach to anaemia management in predialysis chronic kidney disease. $J$ Ren Care 2009, 35(Suppl 2):29-31.

17. Besarab A, Hörl WH, Silverberg D: Iron metabolism, iron deficiency, thrombocytosis, and the cardiorenal anemia syndrome. Oncologist 2009, 14(Suppl 1):22-33.

18. Handelman GJ, Levin NW: Iron and anemia in human biology: a review of mechanisms. Heart Fail Rev 2008, 13:393-404.

19. Clark SF: Iron deficiency anemia: diagnosis and management. Curr Opin Gastroenterol 2009, 25:122-128.

20. Kulnigg S, Gasche C: Systematic review: managing anaemia in Crohn's disease. Aliment Pharmacol Ther 2006, 24:1507-1523.

21. Rozen-Zvi B, Gafter-Gvili A, Paul M, Leibovici L, Shpilberg O, Gafter U: Intravenous versus oral iron supplementation for the treatment of anemia in CKD: systematic review and meta-analysis. Am J Kidney Dis 2008, 52:897-906.

22. Macdougall IC: Iron supplementation in the non-dialysis chronic kidney disease (ND-CKD) patient: oral or intravenous? Curr Med Res Opin 2010, 26:473-482.

23. Gisbert JP, Gomollón F: Common misconceptions in the diagnosis and management of anemia in inflammatory bowel disease. Am J Gastroenterol 2008, 103:1299-1307.

24. Bailie GR, Clark JA, Lane CE, Lane PL: Hypersensitivity reactions and deaths associated with intravenous iron preparations. Nephrol Dial Transplant 2005, 20:1443-1449.

25. Kovesdy CP, Kalantar-Zadeh K: Iron therapy in chronic kidney disease: current controversies. J Ren Care 2009, 35(Suppl 2):14-24.

26. Macdougall IC, Hutton RD, Cavill I, Coles GA, Williams JD: Poor response to treatment of renal anaemia with erythropoietin corrected by iron given intravenously. BMJ 1989, 299:157-158.

27. Tagboto S, Cropper L, Turner J, Pugh-Clarke K: The efficacy of a single dose of intravenous ferric carboxymaltose (Ferinject) on anaemia in a pre-dialysis population of chronic kidney disease patients. J Ren Care 2009, 35:18-23.

28. Brookhart MA, Schneeweiss S, Avorn J, Bradbury BD, Liu J, Winkelmayer WC: Comparative mortality risk of anemia management practices in incident hemodialysis patients. JAMA 2010, 303:857-864.

29. Folb PI: The safety of iron dextran and a comparison with iron sucrose for intravenous use: a short report to the world health organization advisory committee on the safety of medicines.[http://www.who.int/ medicines/areas/quality_safety/safety_efficacy/Addendum.pdf], (last accessed February 3 2011).

30. Lyseng-Williamson KA, Keating GM: Ferric carboxymaltose: a review of its use in iron-deficiency anaemia. Drugs 2009, 69:739-756.

31. Muñoz M, Breymann C, García-Erce JA, Gómez-Ramírez S, Comin J, Bisbe E: Efficacy and safety of intravenous iron therapy as an alternative/adjunct to allogeneic blood transfusion. Vox Sang 2008, 94:172-183.

32. Moore RA, Edwards JE, McQuay HJ: Sildenafil (Viagra) for male erectile dysfunction: a meta-analysis of clinical trial reports. BMC Urol 2002, 2:6.

33. Moore RA, Derry S, Makinson GT, McQuay HJ: Tolerability and adverse events in clinical trials of celecoxib in osteoarthritis and rheumatoid arthritis: systematic review and meta-analysis of information from company clinical trial reports. Arthritis Res Ther 2005, 7:R644-665.

34. Moore RA, Derry S, McQuay HJ: Discontinuation rates in clinical trials in musculoskeletal pain: meta-analysis from etoricoxib clinical trial reports. Arthritis Res Ther 2008, 10:R53.

35. Bailie GR, Mason NA, Valaoras TG: Safety and tolerability of intravenous ferric carboxymaltose in patients with iron deficiency anemia. Hemodial Int 2010, 14:47-54.

36. Funk F, Ryle P, Canclini C, Neiser S, Geisser P: The new generation of intravenous iron: chemistry, pharmacology, and toxicology of ferric carboxymaltose. Arzneimittelforschung 2010, 60:345-353.

37. Jadad AR, Moore RA, Carroll D, Jenkinson C, Reynolds DJ, Gavaghan DJ, McQuay HJ: Assessing the quality of reports of randomized clinical trials: is blinding necessary? Control Clin Trials 1996, 17:1-12.

38. L'Abbé KA, Detsky AS, O'Rourke K: Meta-analysis in clinical research. Ann Intern Med 1987, 107:224-233.

39. Morris JA, Gardner MJ: Calculating confidence intervals for relative risk, odds ratios and standardised ratios and rates. In Statistics with confidence: confidence intervals and statistical guidelines. Edited by: Gardner MJ, Altman DG. London: British Medical Journal; 1995:50-63.
40. McQuay HJ, Moore RA: Using numerical results from systematic reviews in clinical practice. Ann Intern Med 1997, 126:712-720.

41. Van Wyck DB, Mangione A, Morrison J, Hadley PE, Jehle JA, Goodnough LT: Large-dose intravenous ferric carboxymaltose injection for iron deficiency anemia in heavy uterine bleeding: a randomized, controlled trial. Transfusion 2009, 49:2719-2728.

42. Anker SD, Comin Colet J, Filippatos G, Willenheimer R, Dickstein K, Drexler H, Lüscher TF, Bart B, Banasiak W, Niegowska J, Kirwan BA, Mori C, von Eisenhart Rothe B, Pocock SJ, Poole-Wilson PA, Ponikowski P, FAIR-HF Trial Investigators: Ferric carboxymaltose in patients with heart failure and iron deficiency. N Engl J Med 2009, 361:2436-2448.

43. Evstatiev R, Marteau P, Iqbal T, Khalif IL, Stein J, Bokemeyer B, Chopey IV, Gutzwiller FS, Riopel L, Gasche C, FERGI Study Group: FERGIcor, a Randomized Controlled Trial on Ferric Carboxymaltose for Iron Deficiency Anemia in Inflammatory Bowel Disease. Gastroenterology 2011.

44. Clinical Study Report 1VIT04004. Vifor Pharmaceuticals. Data on file: Comparison of the Safety and Efficacy of a Unique Intravenous Iron Preparation (VIT-45) Versus Oral Iron in the Treatment of Anemia in Non-Dialysis Dependent Chronic Kidney Disease. 2007.

45. Qunibi WY, Martinez C, Smith M, Benjamin J, Mangione A, Roger SD: A randomized controlled trial comparing intravenous ferric carboxymaltose with oral iron for treatment of iron deficiency anaemia of non-dialysis-dependent chronic kidney disease patients. Nephrol Dial Transplant 2010.

46. Clinical Study Report VIT-IV-CL-015. Vifor Pharmaceuticals. Data on file: A multicentre, controlled Phase III Study to Compare the Efficacy and Safety of VIT-45 and Venofer in the Treatment of Iron Deficiency Anaemia Associated with Chronic Renal Failure in Patients on Haemodialysis. 2005.

47. Clinical Study Report IVIT04005. Vifor Pharmaceuticals. Data on file: Open Label Extrension Study Evaluating the Long Term safety, Tolerability and Efficacy of an Iron Maintenance Dosing Strategy Utilizing Intravenous VIT-45 in the Treatment of Anemia in Non-Dialysis Dependent (NDD) Chronic Kidney Disease (CKD). 2007.

48. Clinical Study Report 53214. Vifor Pharmaceuticals. Data on file: A multicentre, open-label, single-arm study to investigate the safety and efficacy of intravenous VIT-45 in haemodialysis patients with anaemia. 2004.

49. Covic A, Mircescu G: The safety and efficacy of intravenous ferric carboxymaltose in anaemic patients undergoing haemodialysis: a multicentre, open-label, clinical study. Nephrol Dial Transplant 2010, $25: 2722-2730$.

50. Clinical Study Report VIT-IV-CL-009. Vifor Pharmaceuticals. Data on file: A Multicentre, Controlled, Phase III Study to Investigate the Safety and Efficacy of Intravenous Infusions of Vit-45 In Women Suffering from Post-Partum Anaemia. 2006

51. Breymann C, Gliga F, Bejenariu C, Strizhova N: Comparative efficacy and safety of intravenous ferric carboxymaltose in the treatment of postpartum iron deficiency anemia. Int I Gynaecol Obstet 2008, 101:67-73.

52. Clinical Study Report 1VIT06011. Vifor Pharmaceuticals. Data on file: The Safety and Efficacy of a Hematinic Agent in the Treatment of Postpartum Patients. 2007.

53. Seid MH, Derman RJ, Baker JB, Banach W, Goldberg C, Rogers R: Ferric carboxymaltose injection in the treatment of postpartum iron deficiency anemia: a randomized controlled clinical trial. Am J Obstet Gynecol 2008, 199(435):e1-7.

54. Clinical Study Report 1VIT04002/1VIT04003. Vifor Pharmaceuticals. Data on file: Comparison of the Safety and Efficacy of a Unique Intravenous Iron Preparation (VIT-45) Versus Oral Iron in the Treatment of Iron Deficiency Anemia Secondary to Heavy Uterine Bleeding. 2006.

55. Van Wyck DB, Martens MG, Seid MH, Baker JB, Mangione A: Intravenous ferric carboxymaltose compared with oral iron in the treatment of postpartum anemia: a randomized controlled trial. Obstet Gynecol 2007, 110:267-278

56. Clinical Study Report VIT-IV-CL-03. Vifor Pharmaceuticals. Data on file: A multicentre, open-label, phase I/II, pharmacodynamic and safety study of VIT-45 given in multiple doses for up to 4 weeks to patients with moderate, stable iron deficiency anaemia secondary to a gastrointestinal disorder. 2004.

57. Clinical Study Report VIT-IV-CL-008. Vifor Pharmaceuticals. Data on file: A Multi-Centre, Randomised, Controlled, Phase III Study to Investigate the 
Safety and Efficacy of Intravenous Infusions of VIT-45 in Patients with Iron Deficiency Anaemia Secondary to Chronic Inflammatory Bowel Disease. 2005.

58. Kulnigg S, Stoinov S, Simanenkov V, Dudar LV, Karnafel W, Garcia LC, Sambuelli AM, D'Haens G, Gasche C: A novel intravenous iron formulation for treatment of anemia in inflammatory bowel disease: the ferric carboxymaltose (FERINJECT) randomized controlled trial. Am J Gastroenterol 2008, 103:1182-1192.

59. Clinical Study Report 1VIT05006. Vifor Pharmaceuticals. Data on file: A Multicenter, Randomized, Blinded, Placebo-Controlled, Cross-Over Study to Investigate the Safety and Tolerability of Intravenous VIT-45 in Patients with Iron Deficiency Anemia. 2006.

60. Clinical Study Report CARS 1. Vifor Pharmaceuticals. Data on file: A pilot randomised double-blind Controlled phase III study to comparethe efficacy and safety of Ferinject ${ }^{\circledR}$ and Venofer ${ }^{\circledR}$ versus standard therapy in patients with chronic heart failure, renal failure and iron deficiency (CARS I). 2008.

61. Szczech LA, Bregman DB, Harrington RA, Morris D, Butcher A, Koch TA, Goodnough LT, Wolf M, Onken JE: Randomized Evaluation of efficacy and safety of ferric carboxymaltose in Patients with iron deficiency Anaemia and Impaired Renal function (REPAIR-IDA): rationale and study design. Nephrol Dial Transplant 2010, 25:2368-2375.

62. Zhang AS, Enns CA: Iron homeostasis: recently identified proteins provide insight into novel control mechanisms. J Biol Chem 2009, 284:711-715.

63. Mackenzie EL, Iwasaki K, Tsuji Y: Intracellular iron transport and storage: from molecular mechanisms to health implications. Antioxid Redox Signal 2008, 10:997-1030.

64. Bleackley MR, Wong AY, Hudson DM, Wu CH, Macgillivray RT: Blood iron homeostasis: newly discovered proteins and iron imbalance. Transfus Med Rev 2009, 23:103-123.

65. Straube S, Derry S, Moore RA, McQuay HJ: Pregabalin in fibromyalgia: meta-analysis of efficacy and safety from company clinical trial reports. Rheumatology (Oxford) 2010, 49:706-15.

66. Lau JH, Gangji AS, Rabbat CG, Brimble KS: Impact of haemoglobin and erythropoietin dose changes on mortality: a secondary analysis of results from a randomized anaemia management trial. Nephrol Dial Transplant 2010, 25:4002-4009.

67. Qunibi WY: The efficacy and safety of current intravenous iron preparations for the management of iron-deficiency anaemia: a review. Arzneimittelforschung 2010, 60:399-412.

68. Knight TG, Ryan K, Schaefer CP, D'Sylva L, Durden ED: Clinical and economic outcomes in Medicare beneficiaries with stage 3 or stage 4 chronic kidney disease and anemia: the role of intravenous iron therapy. J Manag Care Pharm 2010, 16:605-15.

\section{Pre-publication history}

The pre-publication history for this paper can be accessed here: http://www.biomedcentral.com/1471-2326/11/4/prepub

doi:10.1186/1471-2326-11-4

Cite this article as: Moore et al:: Meta-analysis of efficacy and safety of intravenous ferric carboxymaltose (Ferinject) from clinical trial reports and published trial data. BMC Blood Disorders 2011 11:4.

\section{Submit your next manuscript to BioMed Central and take full advantage of:}

- Convenient online submission

- Thorough peer review

- No space constraints or color figure charges

- Immediate publication on acceptance

- Inclusion in PubMed, CAS, Scopus and Google Scholar

- Research which is freely available for redistribution 